\title{
INSTAGRAMÁTICA: CARTOGRAFIA DO TEXTO VIRTUAL \& POÉTICA DA LEITURA EM TEMPO REAL
}

\author{
Edmundo de Oliveira Gaudêncio* \\ A todos que tornaram possível a Primeira Feira Literária de Campina Grande - FLIC \\ “Tudo vale a pena quando a alma não é pequena"
}

Fernando Pessoa

\section{Introdução}

Neste ensaio, duas advertências: primeira, a irreverência da forma da escrita, roubada de Deleuze; segunda, devo referir que, em minhas observações, excluo os Infotextos, esses textos infindáveis e infindos, graças aos links que remetem a textos e mais textos, numa leitura potencialmente infinita e que compõem o conteúdo da Wikipedia, essa "concretização virtual" da Grande Biblioteca de Alexandria. Como "textos virtuais", refiro-me apenas a poemas, aforismos, contos, crônicas, poesias, tais como aqueles que, entre nós, nesta Campina Grande, sem dúvidas, cidade-leitora, considerando a quantidade de nomes (para citar apenas alguns, pedindo as necessárias desculpas pelas evidentes omissões) que escrevem e publicam em Redes Sociais, notadamente o Facebook: Maura Pires Ramos e seus poemas; Luciene Aragão de Melo e seus poemas em prosa; Alane Ramos (com seus aforismos, fragmentos de romances, poemas visuais, poemas em prosa); Josafá de Orós e suas poesias; Socorro do Ó Tejo e seus poemas; Geraldo Pinto e seus versos; Alana Agra e suas crônicas de costumes; Horácio de Almeida Lima e suas sátiras; João e Vólia Amaral e suas crônicas; Valdeci Nabude e Eugênio Felipe e seus aforismos; Ramilton Marinho e seus contos regionais ou "causos"; Fred Ozanan e suas charges-poemas; Elizabeth Marinheiro e suas "Tessituras"; Rangel Júnior e sua poesia regional; Gigliola Cavalcante e seus poemas, estrelas brilhantes na Galáxia da Internet, ao lado de cronistas políticos, sociais, culturais, econômicos, históricos que compõem o quadro de escritores do Paraíba online: Arimateia Souza, Ribamildo Bezerra, Alberto Ramos, Rafael Hollanda, Ailton Elisiário, Félix Araújo Neto, Hermano Nepomuceno, José Edmilson Rodrigues, José Mário, Romero Rodrigues, Josemir Camilo, Noaldo Ribeiro, Myrna Maracajá e outros tantos.

\section{Exposição}

Tomo a liberdade de ler-lhes um texto virtual, de minha autoria, o qual teve 8.700 leitores, de acordo com o Relatório Semanal Facebook:

\footnotetext{
*Possui graduação em Medicina pela Faculdade de Medicina de Campina Grande (1978), Mestrado em Sociologia pela Universidade Federal da Paraíba (1987) e Doutorado em Sociologia pela Universidade Federal da Paraíba (2004). Atualmente é professor Associado I da Universidade Federal de Campina Grande e Professor Aposentado da Universidade Estadual da Paraíba. Tem experiência na área de Medicina, com ênfase em Psiquiatria, Psicologia e Sociologia, atuando principalmente nos seguintes temas: luto, logoterapia, morte, ética e educação.
} 


\begin{abstract}
Meu melhor cartão-postal Edmundo Gaudêncio

(Diz Cecília Meireles: "Liberdade de voar num horizonte qualquer, liberdade de pousar onde o coração quiser". Intervindo, conta Dag Hammarskjold que "A viagem mais longa é a viagem interior". Conclui Fernando Pessoa, tomando uma taça de vinho: "Para viajar basta existir")

Para Mércia Maria

Você me conta das belezas dos lugares que você visita - e me diz como desejaria que os visse com meus próprios olhos! Ora, não preciso do mundo preciso de você que olha o mundo, desejando que eu o veja, pudesse vê-lo ou houvesse-o visto com você. A mim o que interessa é que você possa viajar e conhecer o mundo - porque do mundo o que me interessa ter sob os olhos é sua presença, ainda que em estado de ausência (pois entendo que, para você, viajar é preciso, viver é impreciso e ninguém precisa obrigatoriamente estar presente para ser presença!). Mas, claro, sinto saudades, sim - não do pedaço de mundo em que você pisa e em que eu também poderia estar; sinto saudades de você, que, mesmo distante, continuou (depois de partir) e continua (agora) e continuará (sempre e para sempre) aqui. Afinal, desde há muito - para ser exato, desde o dia em que a conheci -, descobri: a Felicidade não mora antes, nem depois - mas neste instante; nem ali, nem acolá - mas neste lado de cá. Não habita lá fora - onde não estou; mas dentro de mim, onde você sempre estará. Por isso meu melhor cartão postal não é desses mundos em que não necessito estar para ser feliz. Meu melhor cartão postal é apenas um retratinho em preto e branco e $3 \mathrm{X} 4$ que do mundo me conta tudo quanto me interessa: em algum lugar do planeta, você se pensa longe, muito longe de mim (sem saber que na verdade se encontra neste onde de nunca saiu nem poderá sair: nesta saudade profunda deste país do até parece que foi ontem escondido dentro de mim...!).
\end{abstract}

Da forma escrita em que está, um texto, este texto, a "mancha gráfica" desta página tem quatro lados, quatro cantos, quatro margens (uma das quais, nos livros, é interna), inúmeras entrelinhas e duas faces, a face que leio e a face reversa.Tudo isso está contido também no texto virtual, tal como se apresenta no écran do celular ou do computador: quatro margens, inúmeras entrelinhas - mas o suporte do texto é completamente diferente (porque nos textos virtuais da Internet o suporte é a luz). Ou seja, o suporte para o texto não é a tela do écran, mas a luz projetada, a partir de dentro, contra a tela do celular ou do computador, luz essa dentro da qual flutuam cardumes e cardumes de letrinhas como se fossem sardinhas ao longo do curso das linhas do texto que, se nos textos impressos chama-se "mancha gráfica", proponho a ideia de brincarmos um pouco com a ideia de que os textos desenham na luz do écran uma "sombra gráfica".

Por decorrência, podemos pensar que, não apenas os textos virtuais, mas todo tipo de texto, inclusive aqueles impressos no papel, é, em maior ou menor medida, virtual - porque, afinal, todo texto escrito não passa da sombra do escrito sonhado.

Como todo texto, o texto virtual também diz e não diz. Diz o que está dito, mas diz também o que não consta no escrito e que só pode ser lido a partir das margens e das entrelinhas. Há as entrelinhas da narrativa do conto, novela, romance; há as entrelinhas da história da lavratura daquele texto/daquele escrito: em que circunstâncias ele foi escrito, quando, como, quem o escreveu; há as entrelinhas dos outros escritos que foram lidos para que se pudesse escrever aquele especifico texto; há as entrelinhas da vida do autor e as entrelinhas da vida de cada leitor - sendo justamente estas as entrelinhas que impedem que um mesmo texto possa ser lido duas vezes: um texto funciona como um rio heraclitiano de palavras nas quais não se mergulha duas vezes, porque uma releitura 
nos mostra o que não conseguimos perceber quando de uma primeira leitura, sendo o mesmo texto e suas outras diferentes leituras, na medida em que nos tornamos outro, entre uma releitura e mais outra. Ou seja, considerando tantas entrelinhas para um escrito, o que se destaca de mais significativo em um texto senão sua condição de "entre", como afirma Gilles Deleuze, e seu estado de quiasma, como diria MerleauPonty, vez que ele apenas se realiza entre o autor que o compõe e o leitor que, graças à leitura, finaliza sua composição, abrindo-o para outras interpretações?

Mas, cá entre nós, por onde anda o texto virtual dentro do celular ou do computador? Não sabendo a isso responder, podemos pensar que o texto virtual situa-se (como todo texto) no Entre o Autor e o Leitor.

Evidentemente que o texto está e não está dentro do celular e/ou dentro do computador - só não sabemos como localiza-lo -, do mesmo modo que não sabemos localizar uma dada emoção, afeto, sentimento na massa cinzenta do cérebro. Ou seja, não sabemos localizar o texto no coração do celular ou do computador, assim como não conseguimos localizar, no cérebro, por exemplo, o exato lugar onde se forma a engrenagem da saudade.

Em todo caso, para que melhor entendamos o que digo, esclareço-me: um texto, qualquer texto, seja concreto (porque impresso), seja virtual, dá-se graças à existência de elementos que lhe são imprescindíveis. Vejamos quais são eles.

Primeiro elemento: o Autor. Autor, dizemos, é aquele que assina o texto. Muitos dos textos virtuais das redes sociais, ditos anônimos, são tomados como sem autoria. $\mathrm{Na}$ verdade, são dotados de autoria desconhecida, pois que, desde que exista escrita de um texto, há autoria. Autoria é a concessão, a um autor, da propriedade de uma obra. É isso que se atribui a alguém, nessa relação sendo chamado de Autor - isso sobre quem Foucault se pergunta quem seja. "Quem é o autor de um texto?". De fato, será que o autor de uma obra cuja escritura levou cinco anos, ao finalizá-la, é o mesmo autor que a iniciou? De certo modo, sim; de certo, não.

Segundo: O Escrito. Isso e/ou aquilo que é dito no texto; o modo ou estilo com que foi lavrado. No escrito, embutidos, ocultos - portanto, virtuais, na exata medida de seus reais -, a História das Línguas, a História da tipologia dos escritos, a História da escrita e do alfabeto, a História da imprensa (para o caso dos livros impressos), a História da tinta, do papel, do stillus, do lápis, da caneta - a História do computador, do celular, do uso da luz como suporte suficientemente sólido para os textos virtuais, e por isso a História social das sombras por trás do écran do computador e do celular, como a DeepWeb.

Terceiro: A Leitura. Ou seja, do lado de cá do escrito, o autor e suas sombras, conhecido ou desconhecido. Do lado de lá, o leitor (ou, como veremos, o lautor). Quem são esses leitores / lautores? Como leem um texto virtual? Mas, antes, como se tem lido, o que se tem lido, ao longo da História da Humanidade? Primeiro, lemos as estrelas, as pegadas de caças, antes que aprendêssemos a ler as linhas das mãos ou adivinhar o futuro nas entranhas de um pombo; depois aprendemos a ler gestos, grunhidos, palavras. Aprendemos a ler o mundo através do tato, do paladar, do olfato, da audição, da visão. Até que por fim aprendemos a ler uma Língua escrita, aprendemos a ler qualquer texto dentro dos limites de nossos conhecimentos sobre uma ou diversas línguas (lembrando que tudo é texto dado à leitura!). Leitura essa que nunca é uma só (embora ainda que diga respeito ao aparentemente mesmo texto): leitura silenciosa ou em voz alta, leitura individual ou coletiva, a leitura pausada dos poemas, a leitura corrida da prosa, cada leitura requerendo um tempo diferente. De idêntico, em toda forma de leitura, o olhar e, entre dois olhares, a página impressa em tinta ou desenhada com luz. 
Quarto: O Leitor. O leitor é o sujeito que lê - mas também a pessoa que se lê, ao ler. É essa entidade que lê o escrito, lê para aquém do escrito, lendo-o para além do dito, porque ler é interpretar e interpretar é dar sentido próprio inclusive àquilo que alguém não desejou dizer. Ler é construir e projetar historicidades. Nesse processo de recriação do criado, de um lado, o olhar do leitor pousado sobre a página - frente a frente ao olhar ausente do escritor, que o espia, não do outro lado da página, mas do outro lado do texto.

Tudo isso nos levar a pensar um texto como dobra entre autor e leitor; entre o ontem da escrita e o amanhã da releitura neste agora de quem o lê.Nesse sentido, a fusão do universo do leitor, graças ao universo da obra, ao universo do autor não é mais que simples dobra entre o real e o virtual que toda coisa é (para citar apenas um exemplo, o tempo: o ontem, em relação ao hoje, dito real, é virtual - assim como o é o amanhã, que torna virtual este agora, sendo tornado virtual pelo depois-de-amanhã).

Entretanto, como lemos, nesta Hipermodernidade? Que elementos cartográficos caberiam ressaltar numa leitura hipermoderna dos chamados textos virtuais?

Para que não digam que eu não lhes avisei que, na verdade, é extremamente variável o número e o ânimo de meus leitores, publiquei outro texto (do qual muito gosto e que lhes leio) - que teve apenas 37 curtidas e três comentários:

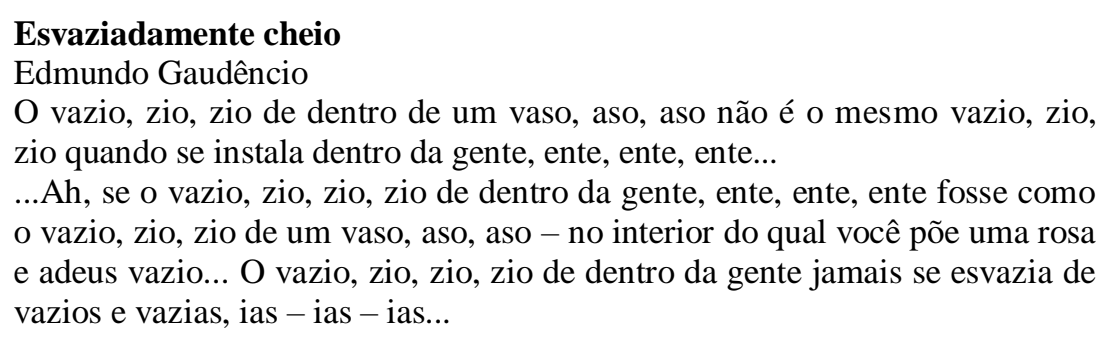

\section{Comentários finais}

Para ir-me finalizando (que se o tempo da Internet é a Internidade, do lado de cá não contamos com a Eternidade), gostaria de perguntar, ainda:

Numa leitura Hipermoderna de textos virtuais, quais os valores que estão em jogo? Creio que estes são pelo menos alguns deles:

A Velocidade (de leitura) - que na Hipermodernidade não há tempo para tempo perdido;

A extensão do texto (preferentemente curto) - que na Hipermodernidade a comunicação há que ser imediata;

O consumo imediato (do conteúdo do texto) - que na Hipermodernidade não cabe a reflexão;

O Anonimato pela posse coletiva, graças à mídia cooperativa e à apropriação frequentemente indébita: Caiu na Net é peixe!

A Efemeridade, a Volatilidade, a Descartabilidade do texto - que na Hipermodernidade tudo é descartável, volátil, efêmero (e mesmo "tudo que é sólido desmancha no ar").

Para uma era da conexão, nada mais justo que a necessária ubiquidade textual: não conseguimos localizar, nas redes sociais, com quem está o texto virtual (que certamente está com todos, mas não é de ninguém - e justo por isso a intervenção do Leitor junto ao Autor em "tempo real"). Impossível interagir com Platão, indagando-o sobre seus "Diálogos" - mas frequentemente possível arguir o autor de textos perdidos 
nas veredas dos grandes sertões do Facebook. Na Hipermodernidade, no que toca aos textos virtuais e sua leitura, não existem mais textos que se contentem com andar nas linhas retas da escrita que compõe a mancha gráfica: os textos virtuais inventaram a leitura labiríntica - e Borges concordaria comigo: junto aos maiores labirintos, os desertos, os espelhos, na Hipermodernidade, quem sabe a morada do Minotauro não seja o infinito labirinto da Internet...? Se não mais existem textos bem comportados, não mais existem leitores (nem nesta Campina Grande, cidade leitora), mas Lautores, como nomeiam Roger Chartier e Rosângela Rojo, leitores que são autores, praticantes do que Julia Kristeva chamou de Escrileitura, na qual e graças à qual, comentários postados nas redes sociais sobre um dado texto obrigatoriamente modificam sua leitura. Nesse processo, nesta Hipermodernidade, de Homo Sapiens nos tornamos, segundo Veen e Wrakking, Homo Zappiens.

Para finalizar, tomo a liberdade de ler-lhes um último texto - o qual serve para ilustrar essa interação entre autoria e leitura da qual e graças à qual o texto não resulta o mesmo, após intervenção de parte do leitor, que o recria com seus comentários.

\section{Ícaro}

(Ícaro, a quem interessar possa, na mitologia grega, filho de Dédalo. Aprisionado em Creta, decidiu fugir. Graças ao auxílio do pai, inventor do labirinto, construiu longas asas belíssimas com cera de abelha e plumas recolhidas em ninhos vazios. Esquecido dos conselhos paternos, "Não voarás rente ao mar. Não voarás próximo do sol”, voando mais alto que deveria, o sol dissolveu-lhe as asas e ele, com isso morrendo, tombou nas águas azuis do oceano, em exato lugar que hoje se chama Mar de Ícaro).

\section{Edmundo Gaudêncio}

Para Mércia e Mahayana, em viagem.

Gosto de pensar trivialidades - até porque gosto de fazer filosofia barata e tudo pode e deve ser objeto da Filosofia. Afinal, se a Filosofia não for capaz de meditar sobre banalidades, não terá competência para pensar o Pensamento, a Alma, a Existência, o Ser Humano. Uma dessas bagatelas a que me refiro é um "Localizador de voo". Você sabe o que é isso, não é? Eu não sabia, juro. Viajo muito pouco. Menos ainda de avião. Pergunto ao Google - e ele me responde: O que é um localizador de passagem aérea? Resposta: é esse documento impresso por computador que contém "Dados do voo - Identificação do número do voo, portão de embarque e o assento escolhido na hora do check-in. Origem e destino - Locais e horários de decolagem e pouso da aeronave. Localizador - Também conhecido como código de reserva, este é o número que identifica sua compra de passagem. Pois bem. Desfeitas as malas, quando do retorno, o que geralmente fazemos com o Localizador de nossa última viagem? Geralmente rasgamos e jogamos fora isso que alguns guardam como suporte para memórias e saudades, não é mesmo? No Localizador, entre os Dados do voo, Itinerário, Ida, Volta. Datas. Números dos voos. Origem, Embarque, Partida, Chegada, qual o lugar das emoções vividas, das sensações vivenciadas e do que se torna desde já memória, talvez saudade? Em tudo, necessário enxergar o não visto. Por exemplo, entre Ida \& Volta e Partida \& Chegada, o trajeto feito, os caminhos pisados e as passadas perdidas, a certeza de que aquele que na partida se foi, não é o mesmo que chega ao seu destino - e muito menos é o mesmo que retorna ao ponto de partida. Entre a data da ida e a data da volta de minha viagem, nove dias. Decerto nove dias a mais, justo por serem nove dias a menos. Na vida não é assim, tantos dias que nos sejam somados, tantos dias nos são subtraídos do cômputo geral dos tempos de nossas existências? Nove dias há pouco ganhos, novos dias já perdidos. Separando as roupas sujas das roupas limpas e guardando-as, ligo o televisor do quarto de dormida. No 
jornal da meia noite, notícias da queda de um avião de passageiros. 137 mortos. Nenhum sobrevivente. Penso no Localizador daquela pessoa que não pode ser localizada nos destroços icarianos do avião. Ida sem volta, partida sem chegada. Penso que, para isso, para amortecer a morte, inventamos sonhos com o Acaso, criamos ilusões de "como-se": ah, se houvesse perdido o voo; ah, se houvesse chegado apenas um minuto atrasado ao aeroporto; ah, se houvesse escolhido outra empresa ou outro dia, ou outra hora, ou outro voo, ou outra vida... Ah, se o acaso houvesse impedido essa viagem sem volta... Olho uma vez mais o Localizador. Dobro-o. Guardo-o dentro do livro que viajou comigo e em quem viajei. Afinal, necessário recordar: todo voo, literal ou figurativamente, pode ser voo de Ícaro.

Dentre os comentários tecidos ao texto acima, destaco estes que, queiramos ou não, graças à interação leitor, leitura, autor, tornou-se outro, texto acrescido por trabalho realizado a pelo menos quatro mãos:

Ângela Albino: Ícaro não reconhecia as asas que fizeram prá ele? Ícaro queria se lançar ao sol, para então, se tornar mar? O limite seria um convite à liberdade? Quantas perguntas para um só domingo! Ao mesmo tempo, quanta filosofia pro cotidiano se agigantar... Obrigada por revelar isso de forma poética pra gente!

Edmundo Gaudêncio: Professora, a Senhora é Incrível! Apenas é dada essa sua capacidade de pensar a quem frequenta a Literatura! Asseguro-lhe: Tantas perguntas me deixam tonto, como tonto Ícaro decerto ficou...! Obrigado pela leitura, pelo comentário, pela postagem - e pelo quanto me leva a refletir sobre as entrelinhas do que escrevi e apenas Você conseguiu ler...! Gostaria de ser seu aluno. Obrigado! Enorme Abraço.

Edmundo Gaudêncio: Em tempo: sinceramente não lhe sei responder...!

Ângela Albino: Nem precisa ... Toda resposta será asa, produzida por Dédalo...

Edmundo Gaudêncio: Ângela Albino: "Toda resposta será asa"...! Posso usar sua frase como "frase gerativa", diria meu Professor Paulo Freire, para uma reflexão - citando, claro, seu nome? Lindo, isto: "Toda resposta é asa" assim como toda pergunta é arremesso sobre precipícios?

Ângela Albino: Edmundo Gaudêncio : em tempo: sinceramente não the sei responder...! Minha asa quebra quando desafio gigantes...

Edmundo Gaudêncio: Diante de tamanhas sem-respostas, de ambas as partes, que tal uma atividade, em uma de suas aulas, sobre um tema, por exemplo, "Por quê, como, onde, quando, até aonde - negam-me meu desejo e meu direito de voar?"

Em suma, era isso. Comecei com Fernando Pessoa: "Tudo vale a pena, quando a alma não é pequena" - a quem parafraseio, com gesto tipicamente hipermoderno: Quando a alma não é pequena, tudo vale à pena.

\section{Referências}

GRAFTON, Anthony. As origens trágicas da erudição: pequeno tratado sobre a nota de rodapé. Trad. Enid Abreu Dobránszky.Campinas, São Paulo: Papirus, 1998. 